\title{
QUESTÕES ÉTICAS EM TRATAMENTO TEMÁTICO DA INFORMAÇÃO E O IMPACTO SOBRE A ACESSIBILIDADE INFORMACIONAL
}

\author{
Daniela Francescutti Martins Hott ${ }^{1}$ \\ Universidade de Brasília (UnB) \\ francescutti69@gmail.com \\ Lais Pereira de Oliveira ${ }^{2}$ \\ $\mathrm{UNESP/UFG}$ \\ laispereira2@yahoo.com.br
}

\begin{abstract}
Resumo
Aborda a ética no tratamento temático da informação dentro da dinâmica do acesso e uso informacional. Objetiva discutir teoricamente questões éticas em tratamento temático da informação e o impacto dessas sobre a acessibilidade informacional. Metodologicamente, tem-se pesquisa de ordem teórica, exploratório-descritiva e de abordagem qualitativa. Emprega revisão de literatura sobre artigos de periódicos, trabalhos publicados em eventos e capítulos de livro do campo biblioteconômico-informacional. A reflexão teórica evidencia pontos de necessário aperfeiçoamento, a fim de que se garanta um processo representativo imbuído de imparcialidade, limitado à atribuição de assunto que seja concernente ao documento, mas que ao mesmo tempo, não traga perdas para o usuário da informação. Delimita-se, por fim, a necessária integração entre o trato temático, a ética e a acessibilidade informacional, em vias de fomentar a cadeia documental em torno da produção, da organização e do uso da informação.
\end{abstract}

Palavras-chave: Tratamento temático da informação. Representação da informação. Ética da informação. Acesso à informação.

\section{ETHICAL ISSUES IN THEMATIC INFORMATION TREATMENT AND THE IMPACT ON INFORMATIONAL ACCESSIBILITY}

\begin{abstract}
It discusses ethics in the subject representation within the dynamics of information access and use. It aims to discuss ethical issues in subject representation and their impact on information accessibility. Methodologically, there is theoretical, exploratory-descriptive research with qualitative approach. It employs a literature review of journal articles, papers published in events, and book chapters in the information-librarian field. The theoretical reflection highlights points of necessary improvement, in order to guarantee a representative process imbued with unbiased, limited to the attribution of subject that concerns the document, but that, at the same time, does not bring losses to the information user. Finally, the necessary integration between subject representation, ethics and information accessibility, in order to foster the documentary chain around the production, organization and use of information, is delimited.
\end{abstract}

Keywords: Subject representation. Information representation. Ethics of the information. Access to information.

\footnotetext{
${ }^{1}$ Doutoranda em Ciência da Informação - UnB (2018- ). Mestre em Ciência da Informação - UnB (2005). Especialista em Documentação e Informação - UFRJ (1994). Créditos cursados em Especialização de Administração de Sistemas de Informação - UFF (1994). Graduada em Arquivologia - UFF (1992).

${ }^{2}$ Docente do curso de graduação em Biblioteconomia da Universidade Federal de Goiás (UFG). Doutoranda em Ciência da Informação pela Universidade Estadual Paulista Júlio de Mesquita Filho (UNESP). Mestre em Ciência da Informação pela Universidade de Brasília (UnB). Bacharel em Biblioteconomia pela Universidade Federal de Goiás (UFG).
} 


\section{INTRODUÇÃO}

Os avanços contínuos das tecnologias de informação e comunicação (TICs), a popularização da Internet e a diversificação de softwares e aplicações disponibilizadas na web trouxeram mudanças na forma de produção, disponibilização, acesso e uso de dados e informações. Também impactaram, sobremaneira, a dinâmica das relações entre as pessoas e a forma como as empresas e organizações divulgam e oferecem seus serviços.

A revolução digital interfere na promoção do acesso à informação, que está diretamente ligada a uma ação profissional de organização, no que a Ciência da Informação (CI) em muito pode contribuir. Afinal, essa tem como base a produção, o uso e as questões de organização e representação informacional (SOUSA; FUJITA, 2012).

Atenta-se para a necessidade de organização da informação - tanto em contexto físico quanto digital - enquanto condição fundamental para a recuperação e acesso, a partir de trabalho intelectual dedicado a representá-la. A representação, designa a constituição de substitutos que serão a chave para a busca pelo usuário. No âmbito da Documentação, a noção de representação está associada à descrição dos aspectos de identificação documental (LOURENÇO, 2017). Representar é, afinal, substituir uma entidade linguística por sua descrição (NOVELLINO, 1996).

Na representação do conteúdo, envidada no tratamento temático da informação (TTI), a ênfase é sobre a construção de atributos de assunto que melhor caracterizem o teor do documento. Contudo, a subjetividade inerente a tal prática, aliada a possíveis vieses na ocasião de análise de assunto pelo profissional, pode incorrer em representações preconceituosas, excludentes, discriminadoras e com impacto negativo sobre a acessibilidade informacional. A representação é, afinal, uma construção (MOREIRA, 2019), entre muitas outras possíveis.

Ademais, em meio a todas essas questões de organização, tratamento e representação da informação, uma parcela de cidadãos ainda permanece à margem da acessibilidade informacional devido a diversas variáveis, tais como: analfabetismo funcional e/ou digital, falta de recursos e/ou de acesso aos equipamentos necessários, ou ainda de acesso à internet, dificuldades quanto à busca e recuperação de dados e informações pertinentes, e problemas relativos à usabilidade e/ou à acessibilidade. A garantia de acesso à informação é, então, verdadeiro desafio que acaba por envolver múltiplos fatores, além da problematização de sua representação a nível de assunto.

Não se deve esquecer, ainda, que o acesso rápido e preciso a informação, constitui-se como objetivo das unidades de informação. Implica, pois, uma dimensão ética que o torna valor 
moral na organização do conhecimento (OC) (EVANGELISTA et al., 2020). Considerando que, no âmbito biblioteconômico, a OC se insere especificamente no aspecto temático (GUIMARÃES, 2001), depreende-se aqui uma importante integração entre o trato temático, a ética e o acesso à informação.

Em termos profissionais, pode-se pensar no trato temático estabelecido cotidianamente nas unidades de informação e daquilo que se prioriza nessa ação. Afinal, a decisão de como representar assuntos é do bibliotecário (OLSON, 2002), profissional que figura como excelente parâmetro ético (PINHO; MILANI, 2020). Assim, há que se pensar na autonomia hipotética de suas escolhas exercidas nas bibliotecas (SÁ, 2013), posto que, uma vez que o bibliotecário tem nas mãos as condições para dizer do que trata um documento, tem também certa liberdade para retratar elementos que considera válidos, ainda que sejam imbuídos de valores pessoais com carga de intolerância e marginalização sobre outrem.

Nesse sentido, a presente investigação objetiva discutir teoricamente questões éticas em tratamento temático da informação e o impacto dessas sobre a acessibilidade informacional. Insere-se, desse modo, em torno da problemática transição, na cadeia documental, do processamento para a saída da informação. Ao aventar essa instância, o estudo traz à tona ponto sensível que é a eticidade das ações de trato informacional e os efeitos no alcance dos conteúdos representados.

Em uma perspectiva teórica, a pesquisa pode contribuir com o rol de conhecimentos produzidos em organização e tratamento da informação. De modo pontual, agrega à reflexão ética sobre a dimensão representativa de assunto e a acessibilidade informacional dela derivada. Em uma perspectiva prática, o estudo pode transmitir ao universo de bibliotecários do processamento técnico da informação, a ponderação necessária na execução dos processos de grande relevância designativa, assim como a devida atenção no final do fluxo informacional, no qual disseminação e acesso são o foco.

\section{INFORMAÇÃO, ORGANIZAÇÃO E CIÊNCIA DA INFORMAÇÃo}

A palavra informação tem raízes latinas (information). Dicionários como Oxford Advanced Learner's Dictionary of Current English (2000), fornecem indicações valiosas sobre a etimologia das palavras e como diferentes autores utilizaram-na no decorrer dos séculos. Deve-se considerar os dois contextos básicos nos quais o termo informação é usado: o ato de moldar a mente e o ato de comunicar conhecimento. 
Informação, à primeira vista, é algo que flui entre um emissor e um receptor. Mas, a definição de informação de Shannon (1948) é quantitativa no que diz respeito a seleções possíveis em um repertório de símbolos físicos. É, de fato, como Underwood (2001) observa, uma teoria de transmissão de sinal ou mensagem, não de transmissão de informação.

Pensando em termos da CI, pode-se compreendê-la como a ciência detida a processos de geração, coleta, organização, interpretação, armazenamento, recuperação, disseminação, transformação e uso da informação. Como uma disciplina, busca criar e estruturar um corpo de conhecimentos de âmbito científico, tecnológico e de sistemas, relacionado à transferência de informação.

Para Capurro e Hjorland (2007) esta definição não contém uma boa identificação do foco específico da Ciência da Informação. Nenhuma ciência deveria ser identificada por meio de suas ferramentas (por exemplo, tecnologias modernas), mas sim, pelo seu objeto de estudo. Como tal, a informação.

É preciso, contudo, identificar a função específica da CI de forma distinta das atividades nas quais outros profissionais são mais qualificados. Essencialmente a partir do fazer técnicointelectual consubstanciado em áreas como a Arquivologia e a Biblioteconomia, já que:

Ao longo dos anos, a Ciência da Informação tem sido influenciada pela evolução da tecnologia da informação. A atuação eficaz do profissional da informação depende de instrumentos tecnológicos que possibilitem o desenvolvimento das diversas atividades informacionais, tendo em vista a complexidade dos serviços, os produtos informacionais e as características dos diferentes públicos, que exigem, cada vez mais, uma compreensão dessas tecnologias (KAFURE, 2010, p. 33).

A organização dos estoques de informação pode, assim, se beneficiar do arsenal tecnológico, apesar de apresentar adversidades e impasses próprios à sua condução que precisam ser observados e discutidos como forma de alcançar o aperfeiçoamento dos processos e práticas que lhe dizem respeito. À medida que os sistemas de informação tornam-se mais globais e interconectados a informação implícita é, muitas vezes, perdida.

No que concerne ao assunto do documento, cuja apreensão é complexa e extremamente subjetiva, essa perda pode ser ainda maior. Esta situação desafia a Ciência da Informação a ser mais receptiva aos impactos sociais e culturais dos processos interpretativos e, também, às diferenças qualitativas entre diferentes contextos e mídias. 


\subsection{Representação no Tratamento Temático da Informação}

Organização e recuperação da informação crescem e tornam-se cada vez mais necessárias desde a explosão informacional pós Segunda Guerra Mundial. A informação passa a ser representada para que se torne acessível (MAGALHÃES; MEDEIROS, 2018). Apesar disso, “[...] os meios de representação estão presentes desde a formação dos primeiros registros idealizados pelo homem." (SILVA; ALBUQUERQUE, 2018, p. 67).

Lima e Alvares (2012, p. 35) explicitam que “[...] a representação da informação é importante objeto de trabalho dos arquivistas, bibliotecários, museólogos, dentre outros profissionais da informação." Na medida em que representam, tornam possível substituir o item completo por uma caracterização, manipulável no sistema de informação. Dessa forma, a representação se condiciona como um recurso substituto de algo (MOREIRA, 2019).

Para Braman (1989) é importante considerar as diferentes profissões envolvidas com a interpretação e seleção de conhecimento. A coisa mais importante em Ciência da Informação (como em política de informação) é entender e disponibilizar a informação como uma força constitutiva na sociedade e, assim, reconhecer a natureza teológica dos sistemas e serviços informacionais.

De modo que, seja qual for o formato, a informação precisa ser devidamente representada para fins de recuperação, isto é, para que se tenha condições de selecionar os conjuntos informacionais contidos nos documentos dispostos em grandes coleções e acervos (DANTAS; CORDULA; ARAÚJO, 2016). A representação pode ser descritiva, voltada a características físicas do item, ou temática, detida ao seu conteúdo (LOURENÇO, 2017).

Essa última, designada no âmbito do tratamento temático da informação, constitui uma das dimensões de organização dos conjuntos informacionais, sendo base para a mesma (RABELO; BENTES PINTO, 2019). Complementar, portanto, à vertente descritiva. É assim que, em uma perspectiva de descrição física, trabalha-se a constituição de atributos essenciais à caracterização do material em termos de autoria, edição, título e etc., e, em uma perspectiva temática, a atenção se volta ao assunto ou conteúdo do item.

A representação temática está presente desde os primórdios da Biblioteconomia (RABELO; BENTES PINTO, 2019), consubstanciada inicialmente nas práticas de ordenação de acervos por assunto e posteriormente na atribuição de termos designativos do conteúdo. Compõe ação fundamental para o tratamento temático da informação, que se volta ao teor do documento (GUIMARÃES, 2009), ou seja, à descrição em termos de conteúdo. 
Com isso, na medida em que o bibliotecário representa tematicamente um documento delineia do que trata o mesmo, caracterizando-o a partir de rótulos, isto é, atribuindo nomes (MILANI; GUIMARÃES, 2014;2017). Ao nomear, o profissional acaba por interferir na construção da informação (OLSON, 2002). Isso porque vai dizer como ela pode ser enxergada, ou seja, sobre que designação ou atributo temático o usuário vai acessá-la. Sobre isso, deve-se ressaltar que:

A pragmática e as pesquisas dedicadas à representação temática e à recuperação da informação apresentam pontos comuns tanto no que se refere à possibilidade de organização da informação, como ao acesso, à mediação e à preservação da memória (RABELO; BENTES PINTO, 2019, p. 69-70).

Sobretudo, porque a discussão não deve ser exclusivamente sobre a instância de representação do assunto mas, acerca do modo como se viabilizará a busca mediada no sistema de informação a partir dos conteúdos representados e, portanto, como se proporcionará acesso. Mais do que isso, há que se ter em mente que:

Como as atividades de organização, representação e difusão do conhecimento são consideradas o centro da atividade profissional na área da informação, uma vez que esses fazeres constituem-se na ponte que une o conhecimento produzido à geração de um novo conhecimento, torna-se necessário refletir e questionar até que ponto os valores éticos estão presentes no tocante à dimensão social desses trabalhos (GUIMARÃES; PINHO, 2006, não paginado).

Organização e representação se inserem, afinal, em uma dimensão social (EVANGELISTA et al., 2020). São mais do que o tecnicismo ordenador. Englobam decidir de forma ética como expressar os atributos de um documento, que serão o canal direto entre a informação nele contida e seu acesso pelo usuário. De modo que o próprio profissional “[...] cumpre um papel social inserido em instituições diversas e numa contínua interação com usuários em busca de informações relevantes." (ARANALDE, 2005, p. 353).

Martínez-Ávila, San Segundo e Zurian (2014) destacam o compromisso ético como um dos aspectos que afetam a profissão e também, o acesso à informação. Reiteram que, nesse sentido, o futuro dos especialistas em organização do conhecimento vai além do treinamento para essa prática. Logo, a postura ética “[...] inclui a busca pelas melhores alternativas para organização, recuperação e disseminação da informação.” (ARANALDE, 2005, p. 354).

Há, portanto, que se trabalhar o reconhecimento de valores em cada instância informacional, a percepção sobre as distintas formas que assumem os conteúdos e o olhar atento em princípios representativos equânimes. Principalmente porque questões ético-informacionais não podem ser relegadas (MEDEIROS, 2015). 
Francelin e Pinho (2011, p. 56-57) ressaltam a necessidade de "[...] levar em conta que tanto o produto quanto o processo de representação devem estar imbuídos da preocupação com a sua utilidade e sua adequação para determinada comunidade ou grupo-alvo." Logo, atividades como classificação, indexação e elaboração de resumos, assim como elementos delas resultantes, quais sejam notações, descritores e resumos documentários, característicos do TTI, precisam ser objeto de reflexão contínua.

Ademais, a representação explicita um ponto de vista (MOREIRA, 2019). Logo, a eticidade no desempenho representativo-informacional ganha força e se mostra como espaço de discussão necessário e urgente. Considerando-se as várias dimensões da informação e as diversas possibilidades de evidenciá-la, a depender da perspectiva que o profissional adotar.

Braman (1989) propiciou uma importante discussão de enfoques para definir informação para os gestores de políticas. Quatro visões principais são identificadas: 1) informação como um recurso; 2) informação como uma mercadoria, 3) informação como percepção de padrões; e 4) informação como uma força constitutiva na sociedade.

Nessa medida, é preciso refletir acerca de todas essas instâncias informativas, pensando a informação como recurso passível de gerar ações e se tornar insumo; ao mesmo tempo, dedicando-se a representá-la mediante os padrões disponíveis, sem esquecer de ponderar a respeito destes, buscando meios de amplificá-los e aprimorá-los. Outrossim, não se pode perder de vista o valor da informação na sociedade e o quão determinante é para a consecução de inúmeras atividades, o que vai exigir um trabalho de representação idôneo e ético para impactar o menos possível de forma negativa, na ação de recuperação.

\subsection{Questões Éticas no Trato Temático e a Acessibilidade Informacional}

A representação não é uma atividade meramente técnica. Trata-se de uma atividade intelectual, que demanda postura consciente e crítica do profissional (GUIMARÃES; PINHO, 2006). Muitos aspectos são envolvidos em seu bojo, tanto na ação pragmática quanto na função social de mediação e disseminação informacional que proporciona, considerando essencialmente o trato informacional em nível temático. A reflexão ética é um caminho para pensar tais questões.

A ética pode ser usualmente compreendida enquanto um conjunto de regras e preceitos de valor moral. De forma ampla, é “[...]uma avaliação crítica da conduta humana perante si mesmo e seus semelhantes." (ARANALDE, 2005, p. 346). Engloba, ainda, a busca pelo bem comum e o bom convívio social (EVANGELISTA et al., 2020). 
Na ação ética, contudo, não há controle, mas, entrega e encontro (GALEFFI, 2020). Isso porque “[...] uma ética não diz respeito apenas aos próprios desejos e suas realizações, mas principalmente a esses desejos em confronto com outros desejos num contexto compartilhado." (ARANALDE, 2005, p. 347-348). Nessa perspectiva, transpondo-se para o aspecto em discussão, há que se conceber um ato representativo informacional que busque a coerência e a ordem assertiva na explicitação do assunto, considerando o alcance desse processo.

A questão ética se encontra, "[...] fortemente presente no universo da Ciência da Informação.” (EVANGELISTA et al., 2020, p. 506). A discussão sobre ética em representação da informação, sobretudo em sua vertente temática, é fundamental. O profissional busca “[...] unidades de sentido para representar documentos, em qualquer suporte, utilizando técnicas para a descrição do seu conteúdo." (ARANALDE, 2005, p. 349).

Outrossim, atribuir assunto é ponto sensível pois "[...] pode ser que, ao criar um substituto documental, o bibliotecário o faça de uma maneira tendenciosa, evocando, consciente ou inconscientemente, suas crenças e seus valores éticos, ou, ainda, veiculando preconceitos." (MILANI; GUIMARÃES, 2014;2017, p. 74). Por se tratar de um substituto, se corporificará como a instância acessada previamente via sistema de informação. Nesse ponto, pode direcionar ou não para a informação desejada.

A depender da forma como foi representado, o assunto pode afastar e repelir o usuário da base de dados. Contudo, esse não é o único risco. Ser um registro inacessível, sem simplesmente retornar a cada busca feita no sistema, é outro ponto da questão que merece atenção.

Outrossim, como agente responsável pelo tratamento temático, a tendência natural é que o profissional se apoie em sua concepção particular sobre os temas que analisa. $\mathrm{O}$ seu ponto de vista, contudo, pode estar carregado de interpretações problemáticas, a tal ponto que venha a deliberar pela exclusão de um conteúdo ou pela não representação do mesmo. "A omissão de um tópico de assunto talvez seja o problema mais visível." (MILANI; GUIMARÃES, 2014/2017, p. 81). Afinal, deixa-se de destacar uma via sobre a qual o item pode ser descoberto e enxergado no sistema de recuperação da informação.

Há que se ressaltar, ainda, que "[...] ao indexar ou classificar um documento, o bibliotecário vislumbra que alguém irá percorrer a ponte informacional que ele acabou de construir ou reformar, a fim de chegar até à informação desejada.” (MILANI; GUIMARÃES, 2014/2017, p. 74). Contudo, isso provavelmente não vai acontecer se a representação for tendenciosa ou excludente. Ou, no mínimo, será grandemente dificultada. 
Diante de tal prática, o ponto de inflexão passa a ser a regra e não a excessão. $\mathrm{O}$ aspecto da acessibilidade se mostra, então, fundamental. Precisa ser pensado desde o momento em que se constrói a representação de assunto, para que esta seja suficientemente representativa e guie o usuário até o conjunto informacional desejado.

Até mesmo porque "[...] a informação é fundamental para vencermos as barreiras do preconceito e da discriminação." (SOUZA et al., 2013, p. 3). E se ela não chega, o que se favorece é uma concepção sem discernimento das coisas. Deixa-se, com uma representação tendenciosa, de viabilizar o acesso. Outro ponto crítico é que isso pode levar a constructos taxativos que denigrem e rotulam inadequadamente certas classes, grupos ou núcleos de sujeitos, fazendo com que sejam enxergados no sistema de informação de modo restritivo, agressivo ou desrespeitoso.

Nesse cenário, a ideia da Internet como uma rede livre e descentralizada, remete a conceitos como diversidade, igualdade e colaboração, onde os ambientes e ferramentas digitais influenciam a sociedade e sofrem mudanças a partir da interação desta com eles. Talvez a expressão mais reveladora dessa nova liberdade seja a transformação da Internet de práticas sociopolíticas.

De fato, vivencia-se uma nova estrutura social, a sociedade em rede global, caracterizada pelo surgimento de uma nova cultura, a cultura da autonomia. Todavia, não basta ter essas informações no ambiente web. Em tese, se não houver estrutura adequada, não se enquandrarão no que Taylor (1984) pontua e detalha como níveis de acesso: físico, legal e intelectual.

Existem dois aspectos no que se refere ao acesso: um é o acesso tecnológico virtual (dispor de rede ou wi-fi para as conexões, as informações estarem dispostas com os requisitos de acessibilidade e de usabilidade, entre outras); e o outro é o acesso físico (hardware disponível). Mas, um sem o outro não proporciona o real acesso. Assim como a ausência de um adequado trabalho de trato temático não permite acessibilidade informacional completa.

Ademais, existem impedimentos ao acesso que não são de ordem exclusivamente legal. Há uma grande carência de recursos humanos e materiais nas instituições, uma descontinuidade de políticas e, em termos representativo-informacionais, a falta de um pensamento éticoreflexivo apropriado às ações desse âmbito. Acaba-se por corroborar, então, com práticas de tratamento informacional de assunto não devidamente representativas.

Acinte dessa ordem replica hostilidade e desrespeito social. Tende-se então, à omissão informacional e, mais do que isso, ao impedimento de acesso e uso, que traz impacto negativo 
porque inviabiliza o pensamento crítico responsável. Assim, uma conduta ética do bibliotecário pode impactar muito além do simples alcance da informação, objeto de representação.

O acesso à informação e a instância usuário precisam ser pensados com a mesma ênfase com que se pensam os processos e instrumentos de trato do conteúdo. Afinal, “[...] um substituto documental defensável é aquele que promove o acesso à informação dentro de um contexto e que dá voz às comunidades de usuários que dele farão uso." (MILANI; GUIMARÃES, 2014;2017, p. 85). Todo o trabalho de tratamento temático, tanto quanto descritivo é, afinal, desenvolvido para proporcionar acesso àquela informação e mostrar que ela existe.

Considerando o catálogo como principal instrumento de recuperação da informação, no âmbito das bibliotecas (SOUSA; FUJITA, 2012), há que se atuar em prol de sua construção ordenada, mas, sem prejuízos no universo de representações que comporta. Isto é, cuidar para que termos, notações e outras estruturas não repliquem visões preconceituosas.

Ao analisar e representar o conteúdo empregam-se linguagens documentárias ou de indexação, que constituem um recurso para organização da informação (MAGALHÃES; MEDEIROS, 2018). Entretanto,

[...] cada sistema de classificação, lista de cabeçalhos de assunto ou tesauro será construído e revisado de acordo com os valores de uma época, os objetivos da instituição e as crenças dos envolvidos nesse processo. Por esse motivo, todos esses sistemas de organização do conhecimento são tendenciosos de alguma maneira (MILANI; GUIMARÃ̉ES, 2014;2017, p. 77).

As linguagens documentárias são construídas, afinal, com base em um corpus discursivo (MEDEIROS, 2015). O ato reflexivo é fundamental, portanto, também no âmbito de tais instrumentos, empregados no tratamento de assunto, para assegurar que a conduta ética seja lembrada nessa ocasião de seleção das ferramentas que guiarão essa prática e sua posterior corporificação no catálogo. Guimarães e Pinho (2006, não paginado) lembram que:

\footnotetext{
Os problemas de tendenciosidade na representação do conhecimento são encontrados desde o momento da criação de instrumentos e ferramentas de representação, como também por parte de profissionais no momento de sua atuação profissional, seja ao classificar ou atribuir conceitos no momento de indexação.
}

Há, portanto, que se pensar cuidadosamente os instrumentos e também buscar capacitação para seu uso e aplicação de forma coerente. $\mathrm{O}$ classificador, o indexador e o elaborador de resumos, têm que estar à altura de suas funções, assim como suficientemente habilitados para desenvolverem análise de assunto e concretizarem a representação temática sem perder de vista o usuário. Sejam eles profissionais distintos ou todos responsáveis pelos mesmos procedimentos. 
Nesse sentido, é preciso orientar o desempenho profissional no tratamento temático para o foco cada vez maior sobre o usuário da informação. Isso sem esquecer da idoneidade e imparcialidade ao dizer do que trata um documento. Assim, “[...] torna-se necessário repensar os instrumentos documentários e a ação não pode estar desvinculada do contexto social." (SOUSA; TOLENTINO, 2017, p. 167). O ato reflexivo cotidiano é crucial, projetando no final da cadeia documental, representado pela disseminação e acesso informacional, junto ao desenvolvimento imparcial das atividades técnicas que permitem representar assuntos.

\section{CONCLUSÃO}

O acesso à informação contribui para o desenvolvimento da sociedade, gerando novas possibilidades para as pessoas, tornando-as aptas a construir uma sociedade mais justa e igualitária. Sem a Internet não teria sido visto o desenvolvimento em larga escala das redes como mecanismo fundamental de estruturação e mudança social em todos os domínios, inclusive no que se refere à acessibilidade informacional.

Ainda assim, demandam-se reflexões no bojo das ações profissionais de organização e representação da informação, como um caminho para a própria evolução do ato representativo e das dimensões possíveis de acesso informacional. Aliás, a Ciência da Informação pode contribuir para as demais áreas do conhecimento que se aproveitam dos processos de organização da informação, inclusive amparando discussões no âmbito ético.

Objetivou-se, aqui, discutir teoricamente questões éticas em tratamento temático da informação e o impacto dessas sobre a acessibilidade informacional. Em certa medida, o enlace revolveu questões comportamentais do profissional da informação, também relativas à sua conduta no uso de instrumentos como as linguagens documentárias e ao necessário ato reflexivo sobre suas ações.

Afinal, a sociedade necessita de profissionais que acompanhem o avanço acelerado das tecnologias da informação e assistivas, bem como da acessibilidade com foco no atendimento de usuários da informação em geral. O mercado exige profissionais do campo da Ciência da Informação com conhecimentos abrangentes e transversais, que possam aplicar ações flexíveis, sendo sensíveis às mudanças e que apresentem habilidades para enfrentamento de momentos decisórios, como de fato são os que se referem ao processamento da informação.

Estudos futuros podem se dedicar à pesquisa aplicada e de campo, buscando avizinharse de constatações junto a unidades de informação, e à ação de trato temático nesse âmbito. Além disso, novos desdobramentos teóricos podem ser aventados, inclusive com aportes incisivos do universo da ética, da moral e das boas condutas. 


\section{REFERÊNCIAS}

ARANALDE, Michel Maya. A questão ética na atuação do profissional bibliotecário. Em Questão, Porto Alegre, v. 11, n. 2, p. 337-368, jul./dez. 2005. Disponível em: https://seer.ufrgs.br/EmQuestao/article/view/124/82. Acesso em: 22 mar. 2020.

BRAMAN, Sandra. Defining information: an approach for policymakers. Telecommunications Policy, v. 13, p. 233-242, 1989. Disponível em: https://www.sciencedirect.com/science/article/abs/pii/0308596189900062. Acesso em: 09 dez. 2019.

CAPURRO, Rafael; HJORLAND, Birger. O Conceito de Informação. Perspectivas em Ciência da Informação, Belo Horizonte, v.12, n.1, p.148-207, jan./abr. 2007. Disponível em: http://portaldeperiodicos.eci.ufmg.br/index.php/pci/article/view/54/47. Acesso em: 25 out. 2019.

DANTAS, Célia Medeiros; CORDULA, Flavio Ribeiro; ARAÚJO, Wagner Junqueira. Análise da representação da informação em modelos entidade relacionamento com base em metadados. Archeion Online, João Pessoa, v. 4, n. 1, p. 40-63, jan./jun. 2016. Disponível em: https://periodicos.ufpb.br/ojs2/index.php/archeion/article/view/32301. Acesso em: 07 nov. 2019.

EVANGELISTA, Isadora Victorino; SANTOS, João Carlos Gardini; GUIMARÃES, José Augusto Chaves; FERNÁNDEZ-MOLINA, Juan Carlos. O acesso à informação como supravalor ético em organização do conhecimento: diálogos entre a literatura científica e as fontes normativas na perspectiva brasileira. RICI: Revista Ibero-Americana de Ciência da Informação, Brasília, v. 13, n. 2, p. 503-521, maio/ago. 2020. Disponível em: https://periodicos.unb.br/index.php/RICI/article/view/24955/26272. Acesso em: 22 mar. 2020.

FRANCELIN, Marivalde Moacir; PINHO, Fábio Assis. Conceitos na organização do conhecimento. In: FRANCELIN, Marivalde Moacir; PINHO, Fábio Assis. Conceitos na organização do conhecimento. Recife: Ed. Universitária da UFPE, 2011. p. 55-65.

GALEFFI, Dante Augusto. Ética, privacidade e confidencialidade de informação em saúde: investigando a ética na sociedade do conhecimento, da informação, da aprendizagem e do controle a partir de uma teoriação polilógica. Informação em Pauta, Fortaleza, v. 5, n. esp., p.9-22, mar. 2020. Disponível em:

http://www.periodicos.ufc.br/informacaoempauta/article/view/43509/100122. Acesso em: 12 jun. 2020.

GUIMARÃES, José Augusto Chaves. Abordagens teóricas de tratamento temático da informação (TTI): catalogação de assunto, indexação e análise documental. Ibersid, Zaragoza, v. 3, p. 105-117, 2009. Disponível em: https://www.ibersid.eu/ojs/index.php/ibersid/article/view/3730/3491. Acesso em: 22 mar. 2020. 
GUIMARÃES, José Augusto Chaves. Perspectivas de ensino e pesquisa em organização do conhecimento em cursos de Biblioteconomia: uma reflexão. In: CARRARA, Kester (org.). Educação, Universidade e Pesquisa. Marília: Unesp-Marília-Publicações; São Paulo: FAPESP, 2001. p. 61-72.

GUIMARÃES, José Augusto Chaves; PINHO, Fabio Assis. Aspectos éticos em organização e representação do conhecimento (O.R.C.). In: ENCONTRO NACIONAL DE PESQUISA EM CIÊNCIA DA INFORMAÇÃO, 7., 2006. Anais [...]. Marília: UNESP, 2006. Disponível em: https://brapci.inf.br/_repositorio/2010/08/pdf_d012df993c_0011665.pdf. Acesso em: 07 nov. 2019.

HORNBY, A. S. Oxford Advanced Learner's Dictionary of Current English. 6th ed. Oxford University: Oxford, 2000.

KAFURE, Ivette. Imagem, usabilidade e emoção. In: MANINI, Miriam Paula; MARQUES, Otacílio Guedes; MUNIZ, Náncy Campos. Imagem, Memória e Informação. Brasília: Ícone Editora e Gráfica, 2010. p. 33-50.

LIMA, José Leonardo Oliveira; ALVARES, Lillian. Organização e representação da informação e do conhecimento. In: ALVARES, Lillian (org.). Organização da informação e do conhecimento: conceitos, subsídios interdisciplinares e aplicações. São Paulo: B4 Editores, 2012. p. 21-47.

LOURENÇO, Cíntia de Azevedo. Representação da informação: sua abordagem nos cursos de Biblioteconomia e nas pesquisas em Ciência da Informação. In: EnReDo - ENCONTRO DE REPRESENTAÇÃO DOCUMENTAL, 1., 2017. Anais [...]. São Carlos: UFSCAR, 2017. Disponível em: http://www.telescopium.ufscar.br/index.php/enredo/enredo/paper/viewFile/95/106. Acesso em: 09 dez. 2019.

MAGALHÃES, Mônica da Silva; MEDEIROS, Graziela Martins de. A representação da informação nos arquivos do IPHAN: uma proposta de tesauro na área de patrimônio cultural. Revista Brasileira de Biblioteconomia e Documentação, São Paulo, v. 14, n. 2, maio/ago. 2018. Disponível em: https://rbbd.febab.org.br/rbbd/article/view/783/1045. Acesso em: 02 dez. 2019.

MARTÍNEZ-ÁVILA, Daniel; SAN SEGUNDO, Rosa; ZURIAN, Francisco A. Retos y oportunidades en organización del conocimiento en la intersección con las tecnologías de la información. Revista Española de Documentación Científica, v. 37, n. 3, p. 1-13, jul./sep. 2014. Disponível em: http://redc.revistas.csic.es/index.php/redc/article/view/856/1135. Acesso em: 09 dez. 2019.

MEDEIROS, Jackson da Silva. Uma abordagem conceitual sobre garantias de representação no gerenciamento da organização de estoques de informação como proposição éticoinformacional. Em Questão, Porto Alegre, v. 21, n. 3, p. 190-210, set./dez. 2015. Disponível em: https://seer.ufrgs.br/EmQuestao/article/view/59340/36049. Acesso em: 12 jun. 2020.

MILANI, Suellen Oliveira; GUIMARÃES, José Augusto Chaves. Problemas relacionados a Biases em Sistemas de Organização do Conhecimento: perspectivas para a representação de assunto. Iris - Informação, Memória e Tecnologia, Recife, v. 3, n. especial, p. 72-92, 
2014/2017. Disponível em:

https://periodicos.ufpe.br/revistas/IRIS/article/view/236189/29018. Acesso em: 09 dez. 2019.

MOREIRA, Walter. Tesauros e ontologias como modelos de sistemas de organização do conhecimento. Brazilian Journal of Information Studies: Research Trends, Marília, v. 13, n. 1, p. 15-20, 2019. Disponível em:

https://revistas.marilia.unesp.br/index.php/bjis/article/view/8277. Acesso em: 22 mar. 2020.

NOVELLINO, Maria Salet Ferreira. Instrumentos e metodologias de representação da informação. Informação \& Informação, Londrina, v. 1, n. 2, p. 37-45, jul./dez. 1996. Disponível em: http://www.uel.br/revistas/uel/index.php/informacao/article/view/1603/1358. Acesso em: 12 jun. 2020.

OLSON, Hope A. Naming is power. In: OLSON, Hope. The power to name: locating the limits of subject representation in libraries. Dordrecht: Springer Science, 2002. p. 1-15.

PINHO, Fabio Assis; MILANI, Suellen Oliveira. Ética em organização do conhecimento: categorização de termos fronteiriços em relação a gênero e sexualidade. Logeion: Filosofia da Informação, Rio de Janeiro, v. 6, n. 2, p. 84-103, mar./ago. 2020. Disponível em: http://revista.ibict.br/fiinf/article/view/5121/4544. Acesso em: 03 nov. 2020.

RABELO, Camila Regina de Oliveira; BENTES PINTO, Virgínia. Tendências nos estudos de Representação Temática da Informação: uma revisão integrativa dos artigos científicos indexados na Brapci. Em Questão, Porto Alegre, v. 25, n. 2, p. 66-88, maio/ago. 2019. Disponível em: https://seer.ufrgs.br/EmQuestao/article/view/82314/52546. Acesso em: 07 nov. 2019.

SÁ, Alzira Tude de. Ler, indexar, representar: o poder que subjaz à ordem das escolhas. Biblos: Revista do Instituto de Ciências Humanas e da Informação, v. 27, n. 1, p. 43-53, jan./jun. 2013. Disponível em: https://periodicos.furg.br/biblos/article/view/3312/2391. Acesso em: 09 dez. 2019.

SHANNON, Claude E. A mathematical theory of communication. Bell System Technical Journal, v. 27, n. 3, p. 379-423, 1948. Disponível em:

http://people.math.harvard.edu/ ctm/home/text/others/shannon/entropy/entropy.pdf. Acesso em: 07 nov. 2019.

SILVA, Jefferson Higino da; ALBUQUERQUE, Maria Elizabeth Baltar Carneiro de. Abordagens da representação da informação na Arquivologia: análise a partir dos Anais da ISKO-Brasil. Biblionline, João Pessoa, v. 14, n. 1, p. 67-79, 2018. Disponível em: https://periodicos.ufpb.br/ojs/index.php/biblio/article/view/38599/20680. Acesso em: 12 jun. 2020.

SOUSA, Brisa Pozzi de; FUJITA, Mariângela Spotti Lopes. Do catálogo impresso ao on-line: algumas considerações e desafios para o bibliotecário. Revista ACB: Biblioteconomia em Santa Catarina, Florianópolis, v. 17, n. 1, p. 59-75, jan./jun. 2012. Disponível em: https://revistaacb.emnuvens.com.br/racb/article/viewFile/822/pdf_71. Acesso em: 07 nov. 2019. 
SOUSA, Brisa Pozzi de; TOLENTINO, Vinicius de Souza. Aspectos machistas na organização do conhecimento: a representação documentária da mulher em instrumentos documentários. Informação \& Informação, Londrina, v. 22, n. 2, p. 166-207, maio/ago. 2017. Disponível em:

http://www.uel.br/revistas/uel/index.php/informacao/article/view/31448/22003. Acesso em: 12 jun. 2020.

TAYLOR, Hugh A. Los servicios de archivo y el concepto de usuario: un estudio del RAMP. Paris: Unesco, 1984.

UNDERWOOD, Mick. Berlo's S-M-C-R Model. Communication, Culture \& Media Studies. Cornwall, UK: 2003. 